\title{
O COMPASSO, O ESQUADRO E A ORDEM DISCRETA: PERFIL SOCIOLÓGICO DOS GRÃO-MESTRES DA MAÇONARIA PARANAENSE, de Tiago Valenciano ${ }^{1}$
}

\author{
Alessandro Cavassin Alves ${ }^{2}$
}

- Enviado em 30/04/2016

- Aprovado em 20/05/2016

Antes de abordarmos sobre a tese de Tiago Valenciano, destacamos ser este mais um profundo e elogiável trabalho de pesquisa tendo como referência o NEP - Núcleo de Estudos Paranaenses, coordenado pelo Prof. Dr. Ricardo Costa de Oliveira (UFPR), também orientador desta tese, e que nos proporciona entender ou pensar o Brasil a partir de nossa realidade local, o Paraná.

A tese de Tiago Valenciano aborda um tema difícil e cheio de "paixões", a maçonaria, e por vezes, cercado de "preconceitos" e de "mitos" devido a sua "ordem discreta" e secreta de organização. Mas, de forma segura e consciente, o autor constrói uma explicação histórica da maçonaria no mundo, no Brasil e no estado do Paraná, tema de sua pesquisa. E procura ir "para além dos segredos", demonstrando a importância desta instituição no desenrolar de nossa história, em especial corroborando com os estudos da atuação da maçonaria no Brasil no século XIX e início do século XX. Mas, avança Valenciano, ao nos propor uma análise atual da maçonaria, na pessoa dos seus Grão-mestres no Paraná.

Portanto, a leitura da tese de Tiago Valenciano contribui imensamente para que repensemos esta instituição de caráter internacional e com objetivos filantrópicos e humanísticos,

\footnotetext{
${ }^{1}$ Tese de autoria de Tiago Valenciano Previatto Amaral, defendida no Programa de Pós-Graduação em Sociologia da UFPR, na linha Instituições e Poder, em 23/03/2015, sob orientação do Prof. Dr. Ricardo Costa de Oliveira. Versão completa disponível na Biblioteca Digital da UFPR - http://www.humanas.ufpr.br/portal/pgsocio/. Acesso em 30.maio.2016.

${ }^{2}$ Doutor em Sociologia. Professor na FASBAM (Faculdade São Basílio Magno), Curitiba, PR e SEED (Secretaria de Estado da Educação do Paraná). Endereço eletrônico: alessandrocavassin@gmail.com
} 
como aponta, também, a pesquisadora Eliane L. Colussi (1998) em seu estudo sobre a maçonaria no Rio Grande do Sul. E, assim, buscarmos, também, perceber como os maçons foram atuando concretamente na sociedade, a partir de sua filosofia organizacional e como influenciaram, por exemplo, na vida política em todo o Brasil.

No Paraná, a força e a presença desta instituição, a maçonaria, começa em 1837, com a Loja Maçônica União Paranaguaense, em Paranaguá e logo "subindo" a serra, chegando a Curitiba e, ao longo do tempo, presente em todo o estado, formando grupos de "irmãos" que podem ajudar e serem ajudados, devido ao pertencimento a esta instituição. Afinal, a maçonaria, por agregar membros de uma elite, através de um processo de recrutamento estratégico (VALENCIANO, 2015, p.28-29), com determinada "posição social”, padrinho, indicação, aceite e iniciação, torna-se também um elo importante para entender as relações de interesse, de decisões e de ampliar círculos ou as chamadas "teias" desta mesma instituição, chegando, consequentemente, a influenciar outras esferas da vida social, como na política. E eis, inclusive, a expressão, a maçonaria como "família" (Ibidem, p.89 e p.123).

Este repensar passa, por exemplo, quando passamos a perceber ao nosso redor as Lojas Maçônicas dentro de nossas cidades. Tomando como um exemplo particular, o Templo Maçônico, denominado Juca Paranhos ou Visconde de Rio Branco ${ }^{3}$, no município de Rio Branco do Sul, região metropolitana de Curitiba, Paraná. Este foi fundado em 26/10/1913, na qual contou com a presença do venerável desta Loja, Coronel Manoel Borges de Macedo. Conduziu a cerimônia de inauguração o delegado do Grande Oriente do Paraná Coronel Antonio Ricardo do Nascimento e foi brindado pela presença o maçom Dr. Generoso Marques dos Santos. E a carta de Regularização foi assinada pelo Dr. Marins Alves de Camargo. Estavam presentes, ainda, inúmeras outras autoridades. Mas, o que estes quatro nomes citados significam politicamente em 1913: o primeiro é filho do ex-prefeito de Curitiba, José Borges de Macedo (maçom); o segundo foi vereador em Curitiba (1887-1889), inclusive assumindo momentaneamente a presidência desta Casa; o terceiro, Dr. Generoso Marques dos Santos, foi um dos mais influentes políticos paranaenses entre o final do século XIX e início do século XX, chegando a ser governador e senador pelo Paraná. Seu nome, uma vez citado, pode ser associado a uma "teia" enorme de influências no mundo político e econômico da época (GOULART, 2014; ALVES, 2015). E o Dr. Marins Alves de Camargo era irmão do, também maçom, Dr. Afonso Alves de Camargo, este último foi também um dos mais

3 Museu Maçônico Paranaense. Loja Visconde do Rio Branco. Resumo histórico. Disponível em: http://www.museumaconicoparanaense.com/MMPRaiz/LojaPRate1973/GOIPR 902_Hist_RioBranco.htm . Acesso em $22 / 03 / 2016$ 
influentes políticos do Paraná na República Velha, chegando a ser governador e senador. Todos descendentes das tradicionais famílias paranaenses (OLIVEIRA, 2001). E o interessante é que em 1975, o então prefeito de Rio Branco do Sul, o maçom Dr. Silas de Faria Pioli, contribui para a construção do novo templo maçônico na cidade como uma "réplica em escala 1/5 do legendário templo do Rei Salomão"4.

A partir deste exemplo particular, buscamos perceber, portanto, a importância da maçonaria na política no início do século XX no Paraná, afinal, as personalidades citadas são importantes e atuantes políticos paranaenses. Tiago Valenciano $(2015$, p.70) também confirma esta ideia de uma rede entre a maçonaria e a política no Paraná, iniciando suas reflexões com o século XIX.

Aqui sugerimos a leitura, também, do artigo de Ana VANALI (2016) sobre a maçonaria no Paraná no século XIX e início do século XX, mas com o objetivo de acompanhar a trajetória do maçom e grande intelectual paranaense Manoel Correia Defreitas, demonstrando como as instituições podem potencializar as ações de seus membros, para este caso, em especial em favor da luta pela abolição da escravatura e pelo republicanismo, sendo um espaço intelectual de ação e proposição de ideias. Conferir, também, para o Paraná as pesquisas de Nelson Bücker, sobre a maçonaria na $1^{\mathrm{a}}$ República.

Enfim, José Borges de Macedo, Manoel Alves de Araujo, Joaquim José Alves, Generoso Marques dos Santos, Joaquim de Almeida Faria Sobrinho, Trajano Joaquim dos Reis, Tertuliano Teixeira de Freitas, Antonio Ricardo do Nascimento, Justiniano de Melo e Silva, Manoel Correia Defreitas, Marins Alves de Camargo, entre muitos outros ${ }^{5}$, são exemplos de políticos paranaenses que eram maçons e importantes lideranças no século XIX e início do XX. Eis a ligação clara da maçonaria na política paranaense.

Mas o foco de análise de Tiago Valenciano não é o século XIX e nem o período da República Velha no Brasil ou no Paraná. Seu objetivo é elaborar um perfil sociológico dos Grãomestres da maçonaria paranaense, a partir de 1941, como se verá adiante. Antes, porém, vamos perceber como o autor constrói o seu trabalho.

\footnotetext{
${ }^{4}$ A:.R:.L:.S:. Juca Paranhos. Templo. Disponível em: http://jucaparanhos.com.br/templo. Acesso em 22/03/2016.

5 Conferir os nomes de maçons políticos em Museu Maçônico Paranaense. Disponível em: http://www.museumaconicoparanaense.com/new/ Acesso em 22/03/2016.
} 
Na primeira parte busca apresentar a "caracterização do objeto", isto é, a maçonaria. Aqui, sua grande preocupação em fazer um discurso acadêmico científico, frente ao perigo de um texto engajado, por vezes tendencioso quanto ao tema. Neste sentido, discute-se a questão da "neutralidade" do pesquisador. As fontes utilizadas são as "públicas", isto é, aquelas que a própria maçonaria disponibiliza, tanto em livros (da própria maçonaria ou de autores que discutem o tema), quanto em seus inúmeros "sítios" eletrônicos, bem como para as biografias dos Grão-mestres. Aqui, também, temos uma ampla revisão bibliográfica de textos acadêmicos sobre a maçonaria, com destaque para a Dra. Eliane L. Colussi (1998), José Murilo de Carvalho (2007), Kennyo Ismail, entre outros.

Uma vez, tendo como referência o que é a maçonaria, pela própria maçonaria, passamos para a segunda e terceira partes do trabalho, que é a perspectiva histórica. Destaca-se, com a leitura, a dinâmica dos acontecimentos na maçonaria, no Brasil como um todo e no Paraná, como ela foi sendo construída e, principalmente, entender como aconteceram suas cisões e dissidências internas. Aqui tomamos a complexidade de como uma organização de caráter secreto também vai tomando rumos distintos e abrindo novas "potências maçônicas" (ver o Grande Oriente do Brasil, GOB e as duas principais dissidências, a Confederação da Maçonaria Simbólica Brasileira, CMSB e a Confederação Maçônica do Brasil, COMAB. No Paraná, a presença do Grande Oriente do Brasil Paraná, GOB/PR, da Grande Loja do Paraná, GLP e do Grande Oriente do Paraná, GOP).

A quarta parte do trabalho reforça seu referencial teórico e a metodologia adotada. Com Pierre Bourdieu e comentadores, discutem-se os conceitos de campo, habitus, capital (econômico, cultural, social e simbólico) e trajetória social (trajetória, enquanto um conceito mais amplo do que a biografia simplesmente, pois visa entender todo o conjunto de relações, oportunidades, capitais que possibilitaram o ator a ter determinada posição social). Da teoria das elites destacam-se os clássicos Gaetano Mosca, Vilfredo Pareto, Wright Mills, Joseph Love e Bert Barickman. E da prosopografia, Lawrence Stone, Christophe Charle, Flávio Heinz entre outros. Aqui, como o próprio autor defende, esta seria uma “opção pela análise conjugada" (VALENCIANO, 2016, p.144). E, quanto ao NEP (Núcleo de Estudos Paranaenses), pesquisa na qual Tiago Valenciano também participa como pesquisador, temos incorporadas na tese as análises de Ricardo Costa de Oliveira, Mônica Helena H. S. Goulart, Alessandro Cavassin Alves, Luiz Demétrio Janz Laibida, Vanderlei Hermes Machado, Marcelo Gonçalves Marcelino, Daiane Carnelós Resende, Roberta Carnelós Resende, Guilherme Tabatcheik e Ana Vanali. 
Mas, o interesse de Tiago Valenciano concentra-se nos Grão-mestres da maçonaria paranaense, discutida na quinta e última parte do seu trabalho de tese, tida como uma "elite estratégica", por se tratar dos líderes desta organização secreta. Eis a originalidade do autor, ao buscar associar "o trinômio maçonaria / sociologia / Paraná". Personagens, porém, que estão divididos em seus três grandes grupos dentro da maçonaria, o Grande Oriente do Brasil - Paraná (GOB/PR), da Grande Loja do Paraná (GLP) e do Grande Oriente do Paraná (GOP), num total de 49 indivíduos. E, questiona-se: Qual é o perfil sócio profissional dos Grão-mestres da maçonaria paranaense? Quais seus capitais sociais, como profissão, carreira maçônica e inserção social?

Para responder a estas e outras questões, o autor levanta, então, a biografia dos Grãomestres paranaenses (VALENCIANO, 2016, p.164-187) e formando uma ficha dos perfis de cada um deles (Ibidem, Anexo V, p.240-268), buscando encontrar os seguintes componentes, "o município de origem, a escolaridade, a relação profissão / ocupação, a atividade política das lideranças maçônicas do Paraná e as conexões interinstitucionais existentes” (Ibidem, p.4).

De posse das biografias de todos estes líderes maçônicos, o autor passa, então, a associar os dados biográficos, que é o exercício da prosopografia (Ibidem, p.187-207). Diz o autor, "é possível olhar para o conjunto de biografias e questionar: qual é, portanto, o perfil sociológico destes Grão-mestres? Quais são os elementos de suas trajetórias que refletem a posição social ocupada (à luz de Wright Mills)? Podemos afirmar que existe sim um perfil delimitado destes personagens?" (Ibidem, p.149). Neste sentido, destacamos a defesa de Valenciano sobre a "maçonaria vista como um campo próprio de ação", de habitus e de campo, utilizando a terminologia de Bourdieu, na qual se constrói ou se consolida capitais.

Enfim, ao terminarmos a leitura da tese de Tiago Valenciano podemos entender melhor a maçonaria e, também, o objetivo do autor, apresentar/conhecer sua “elite estratégica”, os Grãomestres paranaenses.

Portanto, do perfil sociológico destes líderes maçônicos, em sua maioria, são provenientes da capital paranaense, Curitiba. É uma elite altamente escolarizada. Da escolarização temos a questão da profissão e ocupação. O ranking das profissões destes Grão-mestres são os advogados, seguidos de militares, profissionais liberais diversos, servidores públicos, comerciários, médicos e professores. Destes, há uma predominância de bacharéis em Direito e militares. Olhando agora para a ocupação (no sentido de observarmos se o indivíduo atua na área em que ele se formou), novamente se destaca os advogados, os militares e surge a ocupação dos políticos profissionais (pessoas com atuação na política partidária e nos mais variados partidos). E, por fim, se o Grão- 
mestre possui vinculações com outras instituições, além da maçonaria. Cerca de $47 \%$ deles têm mais de uma "conexão interinstitucional", na qual se destacam as chamadas "entidades classistas", isto é, instituições próximas à profissão ou ocupação do líder maçônico.

Enfim, a tese de Tiago Valenciano é mais uma grande contribuição para se pensar a história e a sociedade paranaense, tendo em vista a compreensão do que é o Brasil, nesta dinâmica entre o passado e o presente, entre atores e instituição, entre ideias e comportamentos, de uma "elite estratégica" e suas ações que formam uma "teia" que deve ser entendida.

\section{Referências Bibliográficas}

ALVES, Alessandro Cavassin. (2015) A província do Paraná e sua Assembleia Legislativa (1853 a 1889): a força política das famílias tradicionais. Curitiba: Máquina de Escrever.

CARVALHO, José Murilo. (2007) A construção da ordem: a elite política imperial. Rio de Janeiro: Civilização Brasileira.

COLUSSI, Eliane Lucia. (1998) Plantando Ramas de Acácia: a maçonaria gaúcha na segunda metade do século XIX. Tese em História, Porto Alegre: PUC RS.

GOULART, Mônica H. H. S. (2014) A dança das cadeiras. Análise do jogo político na Assembleia Legislativa do Paraná (1889-1930). Jundiaí, Paco Editorial.

OLIVEIRA. Ricardo Costa de. (2001) O silêncio dos vencedores: genealogia, classe dominante e estado do Paraná. Curitiba: Moinho do Verbo.

(2012) Na teia do nepotismo: sociologia política das relações de parentesco e poder político no Paraná e no Brasil. Curitiba: Insight.

VALENCIANO, Tiago. (2016) O compasso, o esquadro e a ordem discreta: perfil sociológico dos grão-mestres da maçonaria paranaense. Tese (doutorado). Programa de Pós-graduação em Sociologia. Universidade Federal do Paraná: Curitiba.

VANALI, Ana. Pela verdade, pela justiça pelo bem e pela bondade: o Irmão Manoel Correia

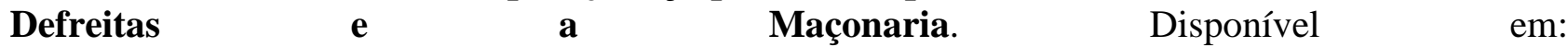
https://www.academia.edu/14034214/Pela_verdade_pela_justi\%C3\%A7a_pelo_bem_e_pela_bonda de_o_Irm\%C3\%A3o_Manoel_Correia_Defreitas_e_a_Ma\%C3\%A7onaria. Acesso em 04/04/2016. 